\title{
Outcomes and prognostic variables of radiofrequency zygapophyseal joint neurotomy in Utah workers' compensation patients
}

This article was published in the following Dove Press journal: Journal of Pain Research

19 May 2017

Number of times this article has been viewed

\author{
Tyler J Christensen \\ M Scott DeBerard \\ Anthony J Wheeler \\ Department of Psychology, Utah State \\ University, Logan, UT, USA
}

Purpose: The prevalence of radiofrequency zygapophyseal joint neurotomy (RFN) has increased substantially across the past decade. Limited research exists that has examined pre-procedure predictors of RFN outcomes, particularly within workers' compensation populations. The purpose of this study was to determine if pre-procedure biopsychosocial variables are predictive of outcomes in a cohort of compensated Utah patients who have undergone RFN.

Patients and methods: This was a retrospective cohort study consisting of a review of pre-procedure medical records and a telephone outcome survey. The sample consisted of 101 compensated workers from Utah who had undergone RFN. Fifty-six patients (55\%) responded to the outcome survey. Patients were an average of 46 months post-neurotomy at the time of follow-up. Outcome measures included patient satisfaction, disability status, Roland-Morris Disability Questionnaire, Stauffer-Coventry Index, and Short-Form Health Survey-36 (v.2). Statistical techniques utilized included frequencies, mean comparisons, and logistic and multiple regressions.

Results: Forty percent of patients were totally disabled at the time of follow-up. Lawyer involvement, older age, and a positive history of depression were predictors of poor outcomes in logistic and multiple regression equations.

Conclusion: Presurgical biopsychosocial variables were predictive of multidimensional patient outcomes, and a high rate of total disability was observed. Additional research on the effectiveness of RFN for workers' compensation patients is recommended.

Keywords: radiofrequency denervation, facet joint, chronic spine pain, injured workers, nonoperative pain treatment

\section{Introduction}

The societal, economic, and occupational costs of spine-related pain in industrialized countries have been well documented throughout the spine literature. A national survey from 2002 indicated that low-back pain (LBP) is the most common type of pain reported by adults in the the United States. ${ }^{1}$ LBP is estimated to account for between $\$ 20$ billion and \$50 billion in annual spending in the US, placing a substantial burden on the health payer system at all levels. ${ }^{2}$ Moreover, spine-related pain is the most common cause of physical disability and also the most cited reason for filing a workers' compensation claim. ${ }^{3}$

According to the criteria established by the International Association for the Study of Pain, ${ }^{4}$ pain originating from the zygapophyseal joints has been implicated in $15-45 \%$ of patients with LBP, $36-67 \%$ of patients with neck pain, and $34-48 \%$ of patients with thoracic pain. ${ }^{5,6}$ Degenerative changes in the zygapophyseal joints
Correspondence: M Scott DeBerard Department of Psychology, Utah State University, Logan, UT 84322-2810, USA

$\mathrm{Tel}+\mathrm{I} 435797$ |462

Fax + | 435797 |448

Email scott.deberard@usu.edu 
(in particular osteoarthritis and inflammation) can cause chronic irritation to spinal nerves and result in chronic pain. ${ }^{7}$ Radiofrequency neurotomy (RFN) is a common treatment for zygapophyseal joint-related pain and involves denervating pain-provocating nerves in an attempt to block neural transmission and subsequently provide long-lasting pain relief. ${ }^{8}$ Zygapophyseal joint interventions rank second only to epidural steroid injections as the most commonly used pain management procedure in the US, and there has been more than a $200 \%$ increase in utilization in the Medicare population within the last decade. ${ }^{9}$

The overall clinical efficacy of RFN is considered somewhat controversial given a lack of high-quality randomized placebo-controlled trials and somewhat inconsistent findings across several systematic literature reviews. ${ }^{8,10-14}$ For example, a recent systematic review by the American Society of Interventional Pain Medicine concluded "good" evidence of lumbar and cervical RFN for short- and long-term pain relief based upon six positive randomized controlled trials (RCTs) and ten positive observational studies. ${ }^{13,14}$ Another recent systematic review and meta-analysis of five RCTs determined that lumbar RFN is likely more effective than placebo in terms of pain control and functional improvement, although the overall quality of the studies included in the review was considered "low", and the authors believed that the results should be interpreted with caution. ${ }^{8}$ Much of the controversy regarding the efficacy of RFN has been perpetuated by two double-blind, placebo-controlled studies showing no or minimal benefit for RFN compared to sham lesioning. ${ }^{15,16}$ Several authors have argued that these and other RCTs and observational studies in this area are flawed based upon lack of properly administered pre-procedure diagnostic blocks, improper patient selection, and other critical procedural variations. ${ }^{10,13,17-19}$ More recent studies addressing these very stringent patient selection and technique issues have shown substantially more positive outcomes for lumbar RFN. ${ }^{17,18}$ For example, the MacVicar et al study examined 106 patients selected on the basis of complete pain relief following controlled dual medial branch blocks. ${ }^{18}$ They determined that $53-58 \%$ of patients across two practices achieved successful outcomes (complete pain relief for 6 months, complete restoration of physical activities of daily living, and return to work) after RFN, and these outcomes were maintained across 15 months following the first RFN procedures and 13 months following repeat treatments. Another prospective study of lumbar RFN that utilized very stringent patient selection and technique protocols found that $60 \%$ of patients evidenced at least $90 \%$ pain relief at 12 months. ${ }^{19}$
Given the significant variability in RFN outcomes across many studies, it is important to identify pre-procedure patient risk factors for poor outcomes. It has long been assumed that workers' compensation patients are typically at a greater risk for poor outcomes across most surgical interventions for chronic pain, ${ }^{20-22}$ although this has yet to be established in the case of RFN. Interestingly, only two studies have examined workers' compensation status with one showing no relationship with RFN outcomes ${ }^{17}$ and the other study showing better RFN outcomes in patients receiving compensation. ${ }^{23}$ There have also been no published RFN studies that have solely examined compensated patient outcomes. Numerous studies in spine surgery have also consistently found that presurgical psychosocial variables are consistent correlates of outcomes, particularly among compensation patients, ${ }^{24-28}$ although this has also not been established in the RFN literature. We are aware of only one observational trial that linked depression with shorter duration of pain relief following RFN. ${ }^{29}$

This study has three primary purposes: 1) to characterize pre-RFN biopsychosocial patient variables in a sample of worker's compensation patients who have undergone percutaneous RFN, 2) to characterize patient outcomes associated with RFN, and 3) to determine if presurgical biopsychosocial variables are predictive of outcomes following the procedure.

\section{Materials and methods Study design}

This was a retrospective cohort study consisting of a medical record review to gather pre-procedure patient information and a telephone outcome survey conducted at least 3 months post-procedure. The institutional review board at Utah State University approved this study, and the Workers' Compensation Fund of Utah (WCFU) provided permission to access patient medical records and contact patients for the follow-up survey. All patients provided verbal informed consent prior to participating in the outcome survey. Strict confidentiality of all patient data was maintained throughout this study.

\section{Patient sample}

All patients who had underwent at least one RFN treatment at the cervical, thoracic, or lumbar level and were at least 3 months posttreatment were eligible for inclusion $(N=101)$. Patients were identified via Current Procedural Terminology codes in WCFU databases. Patients received RFN treatment as a result of a work-related injury and were covered by WCFU for medical and disability costs. WCFU insures approximately $65 \%$ of workers within the State of Utah. 
Patients received their index RFN procedures between August 2008 and February 2009.

\section{Medical record information}

The author obtained medical record and compensation data onsite from the WCFU database using a medical chart review form. Categories of information gathered via this form included demographics, general health, surgical history, psychosocial status/history, litigation status, compensation costs, diagnosis and procedure, medication usage, and additionally required pain interventions. Data were coded using a modified medical chart review instrument designed by one of the authors to study lumbar fusion outcomes in a similar workers' compensation sample..$^{21,22,25}$ The coding instrument was adapted to fit the specific purposes of examining correlates and outcomes in RFN. For example, it was important to code the number of diagnostic nerve blocks administered as well as the number and location of coagulated nerves.

\section{Patient outcome survey}

The outcome survey consisted of five different measures, the first being a five-item patient satisfaction questionnaire (e.g., whether they would have the procedure again) that has been used in previous research on patients who had underwent compensated lumbar fusion and discectomy. ${ }^{21,22,25}$ The Stauffer-Coventry Index (SCI $)^{30}$ assessed outcomes across four domains (pain relief, employment status, physical limitations, and medication usage). Though never used to assess RFN outcomes, the SCI has been used in previous studies of low-back surgical procedures. ${ }^{21,22}$ The RolandMorris Disability Questionnaire (RMDQ) was used to evaluate dysfunction associated with LBP. ${ }^{31}$ The Short-Form Health Survey-36 (SF-36) (v.2) is a widely used survey of general health that assesses eight dimensions of health-related quality of life, namely, physical functioning, role-physical, bodily pain, general health, vitality, social functioning, roleemotional, and mental health. ${ }^{32}$ Finally, disability status was assessed via the medical chart review and verified during the telephone survey.

\section{Results}

Table 1 displays the demographic and other characteristic information for the 101 patients included in the cohort, of which $74 \%$ were male with a mean age of 46.2 years (standard deviation $[\mathrm{SD}]=11.74$ ). The average body mass index was 27.64, which places a majority of patients in the overweight category (25.0-29.9). Slightly $>37 \%$ of patients had undergone at least one back or neck operation (e.g., fusion, discectomy) prior to their first neurotomy. Thirty-six percent of patients had a high school degree/general educational development, and most were nonsmokers (60.4\%). A depression diagnosis was reported in over half of the patients $(52.5 \%)$,

Table I Comparisons of select patient variables for respondents versus nonrespondents

\begin{tabular}{|c|c|c|c|c|}
\hline \multirow[t]{2}{*}{ Patient variables } & \multirow{2}{*}{$\begin{array}{l}\begin{array}{l}\text { Respondents } \\
(n=56)\end{array} \\
\text { Means or } \\
\text { proportion (\%) } \\
\end{array}$} & \multirow{2}{*}{$\begin{array}{l}\text { Nonrespondents } \\
(n=45) \\
\text { Means or } \\
\text { proportion }(\%) \\
\end{array}$} & \multirow{2}{*}{$\begin{array}{l}\text { t or chi- } \\
\text { square } \\
\text { p-value }\end{array}$} & \multirow[t]{2}{*}{$\begin{array}{l}\text { Effect size } \\
\text { (SMD/Phi) }\end{array}$} \\
\hline & & & & \\
\hline Age & 46.95 & 45.16 & 0.45 & 0.14 \\
\hline Body mass index & 27.44 & 27.91 & 0.71 & 0.07 \\
\hline Smoking status at the time of neurotomy (\% yes) & 32.14 & 48.88 & 0.09 & -0.17 \\
\hline Depression diagnosis (\% positive) & 50.00 & 55.56 & 0.58 & -0.06 \\
\hline Case manager (\% positive) & 51.79 & 46.67 & 0.61 & 0.05 \\
\hline Lawyer involvement (\% positive) & 28.57 & 35.56 & 0.45 & -0.08 \\
\hline Prior back/neck surgery & & & 0.53 & -0.12 \\
\hline None & 60.71 & 62.22 & & \\
\hline One & 14.29 & 20.00 & & \\
\hline Two & 12.50 & 6.67 & & \\
\hline Three or more & 12.50 & II.II & & \\
\hline Prior WCF claims & & & 0.35 & -0.09 \\
\hline None & 26.79 & 35.56 & & \\
\hline One or more & 73.21 & 64.44 & & \\
\hline Diagnostic nerve blocks & & & 0.56 & -0.06 \\
\hline One & 80.36 & 75.56 & & \\
\hline Two & 19.64 & 24.44 & & \\
\hline
\end{tabular}

Notes: Omnibus chi-square $=10.87, \mathrm{df}=9, p=0.29$. ${ }^{\mathrm{a}} \mathrm{Effect}$ sizes based upon univariate analyses. Abbreviations: SMD, standardized mean difference; WCF, Workers' Compensation Fund. 
and $31.7 \%$ had hired a lawyer to represent their compensation claim. All patients received at least one "positive" diagnostic nerve block prior to RFN. Of the 101 blocks, $85(84.2 \%)$ were medial branch blocks, and the remainder $(15.8 \%)$ involved intra-articular injections. A total of 31 physicians were involved in performing these injections. A number of blockade agents were utilized, with the most prevalent being lidocaine (31\%), bupivocaine $(24.2 \%)$, marcaine $(18.0 \%)$, and xylocaine $(13.9 \%)$. Of the total number of patients, $29.7 \%(30 / 101)$ received two diagnostic nerve blocks prior to RFN with 63.3\% (19/30) receiving the same anesthetic agent administered in the initial blockade. The criteria for "positive" blockade response varied significantly across practitioners: $15 \%$ viewed a $50 \%$ pain reduction as positive, $65 \%$ viewed $>80 \%$ pain reduction as positive, and $25 \%$ did not report their criteria for positive response in procedure reports. Only $38.6 \%$ of patients $(29 / 101)$ reported a $100 \%$ reduction of their pain level after the first blockade versus $26.6 \%$ $(8 / 30)$ in the second blockade. None of the patients received placebo blocks. RFN was performed on the lumbar spine in 70 cases, cervical in 24, thoracic in one, and multiple spine regions in six. A total of 30 physicians performed these procedures. Of the total number of practitioners, $85.4 \%$ appeared to use a parallel electrode placement and made at least two lesions in the target nerve. Average heat of the electrode was $77.3^{\circ} \mathrm{C}$, and $74.3 \%$ of practitioners used $80^{\circ} \mathrm{C}$. Average duration of coagulation was 80 seconds (54.8\% of the practitioners used 90 seconds, and $29.0 \%$ used 60 -second duration). In the vast majority of patients, neurotomy procedures targeted more than one vertebral segment, with close to $43 \%$ treated at two segments and $45 \%$ treated at three or more segments. This was the first neurotomy for $59.4 \%$ of patients, whereas $27.7 \%$ had a total of two prior, $6.9 \%$ had three prior, and another $6.9 \%$ underwent four or more prior RFN procedures.

\section{Follow-up rate and responder versus nonresponder analyses}

The overall follow-up rate for the outcome survey was $55.4 \%$ (56/101). Comparison of demographic, psychosocial, and medical variables across responders and nonresponders was carried out in an effort to determine if the follow-up sample may have been differentially biased based upon preprocedural variables. Table 1 presents these analyses. None of these comparisons were statistically significant, and all effect size calculations were small in magnitude. We concluded that the follow-up sample was likely not differentially biased from the nonresponder sample.

\section{Patient satisfaction items}

A summary of patient satisfaction frequencies is presented in Table 2. As may be seen, $30.4 \%$ of patients felt that the pain was better than they expected following RFN. Of the total number of patients, $62.6 \%$ felt that their quality of life had not changed or worsened as a result of RFN. Slightly more than a half (55\%) of the patients also indicated that their back/neck/leg pain was either somewhat or much worse than they expected after treatment. Slightly less than a half $(44.6 \%)$ of the respondents said that they would not choose to undergo RFN again.

\section{Disability status}

Of the total number of patients, $39.3 \%$ were totally and permanently disabled at the time of follow-up.

\section{Roland-Morris Disability Questionnaire}

Patients had an average RMDQ score of 14.39 (SD =5.66), a figure slightly above the cutoff line for "poor" outcome at 14.

Table 2 Patient satisfaction with outcomes of radiofrequency neurotomy

\begin{tabular}{|c|c|c|}
\hline Outcome category & $\begin{array}{l}\text { Frequency } \\
(n=56)\end{array}$ & $\%$ \\
\hline \multicolumn{3}{|c|}{ Back/neck/leg pain after neurotomy } \\
\hline Worse than expected & 17 & 30.4 \\
\hline No worse or better & 22 & 39.2 \\
\hline Better than expected & 17 & 30.4 \\
\hline \multicolumn{3}{|l|}{ Quality of life } \\
\hline Great improvement & 7 & 12.5 \\
\hline Moderate improvement & 5 & 8.9 \\
\hline Little improvement & 9 & 16.1 \\
\hline No change & 24 & 42.9 \\
\hline A little worse & 3 & 5.4 \\
\hline Moderately worse & 6 & 10.7 \\
\hline Much worse & 2 & 3.6 \\
\hline \multicolumn{3}{|l|}{ Back/neck/leg pain now } \\
\hline Much better & 5 & 8.9 \\
\hline Somewhat better & 7 & 12.5 \\
\hline What I expected & 8 & 14.3 \\
\hline Somewhat worse & 14 & 25.0 \\
\hline Much worse & 17 & 30.4 \\
\hline No expectation & 5 & 8.9 \\
\hline \multicolumn{3}{|c|}{ Satisfaction with back/neck condition } \\
\hline Extremely dissatisfied & 19 & 33.9 \\
\hline Very dissatisfied & 16 & 28.6 \\
\hline Somewhat dissatisfied & 8 & 14.3 \\
\hline Neutral & 5 & 8.9 \\
\hline Somewhat satisfied & 6 & 10.7 \\
\hline Very satisfied & 1 & 1.8 \\
\hline Extremely satisfied & 1 & 1.8 \\
\hline \multicolumn{3}{|c|}{ Retrospectively, would you choose to have neurotomy done again? } \\
\hline Yes & 30 & 53.6 \\
\hline No & 25 & 44.6 \\
\hline Undecided & 1 & 1.8 \\
\hline
\end{tabular}


Consequently, $64.3 \%$ of patient scores were considered high enough to surpass the "poor outcome" threshold.

\section{Stauffer-Coventry Index}

Frequencies for the SCI are presented in Table 3. As may be seen, the majority of patients $(71.4 \%)$ reported poor outcomes (0-25\% pain improvement) relative to pain relief following RFN. A majority of patients achieved either good (return to previous work) or fair outcome regarding post-procedure employment status. Thirty-seven percent of patients reported good outcomes in terms of post-procedure physical functioning. The majority of patients (69.6\%) were occasionally or regularly using narcotic analgesics to manage pain at the time of follow-up.

\section{Short-Form Health Survey-36}

Table 4 displays the means and SDs of the SF-36 subscales for this study as well as the norms from the general US population and the norms for patients with back pain/sciatica. Standardized mean difference effect sizes were calculated, and, as may be seen, effect sizes were quite large for comparisons with the US population. This suggests that post-RFN patients rate their quality of life much worse than the typical US population. Effect sizes were also, in most cases, quite large when comparing RFN patients with back pain/sciatic norms as well.

\section{Using pre-procedure variables to predict outcomes}

Tables 5 and 6 include the zero-order correlations of patient variables with outcome variables. As may be seen, age, history of depression, and lawyer involvement were consistent statistically significant correlates of patient outcomes. Multivariate analyses were used to predict patient outcomes using a five-variable model of pre-procedure risk factors. Table 7 indicates the results of a logistic regression using these variables to predict disability status, a model that was statistically significant (chi-square $=22.79, p<0.001$ ). Patient age and lawyer involvement in the compensation claim both had Wald values that were statistically significant in the model. The overall hit rate for the model was $80.4 \%$, with specific hit rates of $85.3 \%$ for predicting nondisabled patients and $72.7 \%$ for predicting disabled patients at follow-up.

The remaining analyses in the current study used simultaneous-entry multiple regression and the five-variable model mentioned above to predict multidimensional physical and mental health outcomes via the summary and subscale scores of the SF-36 (v.2). The regression model

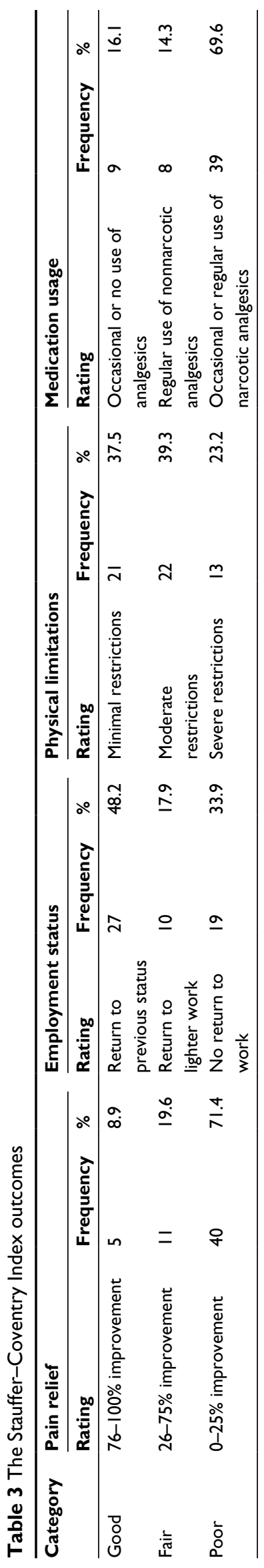


Table 4 SF-36 (v.2) multidimensional health outcomes and comparisons

\begin{tabular}{|c|c|c|c|c|c|}
\hline \multirow[t]{2}{*}{ SF-36 subscale } & $\begin{array}{l}\text { Neurotomy } \\
\text { sample }\end{array}$ & $\begin{array}{l}\text { General } \\
\text { population }\end{array}$ & $\begin{array}{l}\text { General } \\
\text { population }\end{array}$ & $\begin{array}{l}\text { Back pain/ } \\
\text { sciatica }\end{array}$ & $\begin{array}{l}\text { Back pain/ } \\
\text { sciatica }\end{array}$ \\
\hline & $M(S D)$ & $M(\mathrm{SD})$ & Effect size $^{b}$ & $M(S D)^{c}$ & Effect size $^{b}$ \\
\hline Physical functioning & $33.9(12.3)$ & $50.0(10.0)$ & -1.6 & $46.6(11.3)$ & -1.1 \\
\hline Role functioning & $34.6(11.8)$ & $50.0(10.0)$ & -1.5 & $46.4(11.4)$ & -1.0 \\
\hline Pain severity & $34.1(9.5)$ & $50.0(10.0)$ & -1.6 & $44.6(9.3)$ & -1.1 \\
\hline General health & $39.1(10.1)$ & $50.0(10.0)$ & -1.1 & $46.5(10.6)$ & -0.7 \\
\hline Vitality & $39.9(11.1)$ & $50.0(10.0)$ & -1.0 & $46.5(10.2)$ & -0.6 \\
\hline Social functioning & $40.8(13.6)$ & $50.0(10.0)$ & -0.9 & $46.9(11.2)$ & -0.5 \\
\hline Role-emotional functioning & $44.4(11.4)$ & $50.0(10.0)$ & -0.6 & $47.6(11.3)$ & -0.3 \\
\hline Mental health functioning & $43.9(12.4)$ & $50.0(10.0)$ & -0.6 & $47.6(10.9)$ & -0.3 \\
\hline Physical component summary & $32.2(10.6)$ & $50.0(10.0)$ & -1.8 & $45.6(10.8)$ & -1.2 \\
\hline Mental component summary & $47.1(11.7)$ & $50.0(10.0)$ & -0.3 & $47.9(I I .0)$ & -0.1 \\
\hline
\end{tabular}


between means $(M)$ divided by normative sample SD. cNorms for sample comorbid condition: back pain/sciatica (in the past 6 months) with hypertension; $N=48$.

Abbreviations: SF-36, Short-Form Health Survey-36; SD, standard deviation.

Table 5 Correlations of pre-neurotomy variables with outcome variables

\begin{tabular}{lcccccc}
\hline Patient variable & $\begin{array}{l}\text { SCI: pain } \\
\text { relief }\end{array}$ & $\begin{array}{l}\text { SCI: return to } \\
\text { work status }\end{array}$ & $\begin{array}{l}\text { SCI: physical } \\
\text { restrictions }\end{array}$ & $\begin{array}{l}\text { SCI: pain } \\
\text { medications }\end{array}$ & $\begin{array}{l}\text { Outcome } \\
\text { variables }^{\mathbf{a}}\end{array}$ & $\begin{array}{l}\text { Disability } \\
\text { status }^{2}\end{array}$ \\
\hline Age & 0.12 & 0.24 & $0.40^{*}$ & -0.13 & 0.22 & $0.36^{*}$ \\
Body mass index & -0.25 & 0.14 & 0.10 & -0.16 & 0.10 & 0.08 \\
Smoking & -0.02 & 0.02 & -0.02 & 0.12 & 0.22 & 0.15 \\
History of depression & -0.14 & 0.20 & $0.28^{*}$ & $0.38^{*}$ & $0.38^{*}$ & $0.29^{*}$ \\
Case manager assigned & -0.06 & 0.09 & 0.01 & 0.12 & 0.09 & 0.04 \\
Lawyer involvement & -0.06 & $0.45^{*}$ & $0.32^{*}$ & $0.28^{*}$ & $0.54^{*}$ & $0.46^{*}$ \\
Prior back/neck surgery & 0.13 & -0.01 & $0.26^{*}$ & 0.13 & 0.13 & $0.33^{*}$ \\
Prior WCF claims & -0.04 & -0.01 & -0.06 & 0.04 & 0.04 & 0.06 \\
Diagnostic nerve blocks & 0.01 & 0.03 & $-0.32^{*}$ & $-0.29 *$ & -0.19 & -0.21 \\
\hline
\end{tabular}

Notes: aHigher scores equate to worse outcomes/functioning. $*_{p} \leq 0.05$.

Abbreviations: SCl, Stauffer-Coventry Index; WCF, Workers' Compensation Fund.

Table 6 Correlations of pre-neurotomy variables with SF-36 subscales and composite scales

\begin{tabular}{|c|c|c|c|c|c|c|c|c|c|c|}
\hline \multirow[t]{2}{*}{ Patient variable } & \multicolumn{10}{|c|}{ SF-36 subscale ${ }^{a}$} \\
\hline & PF & $\mathbf{R P}$ & BP & GH & VT & SF & RE & MH & PCS & MCS \\
\hline Age & $-0.34^{*}$ & -0.27 & -0.11 & -0.09 & -0.16 & -0.14 & -0.03 & 0.02 & $-0.33^{*}$ & 0.04 \\
\hline Body mass index & -0.24 & -0.05 & -0.10 & -0.13 & -0.09 & -0.14 & 0.03 & -0.13 & -0.17 & -0.05 \\
\hline Smoking & -0.13 & -0.26 & -0.12 & 0.09 & 0.07 & -0.23 & -0.19 & -0.26 & -0.07 & -0.20 \\
\hline History of depression & $-0.39 *$ & $-0.47^{*}$ & $-0.48^{*}$ & -0.09 & $-0.37^{*}$ & $-0.43^{*}$ & $-0.59 *$ & $-0.32 *$ & $-0.33^{*}$ & $-0.44^{*}$ \\
\hline Case manager assigned & -0.12 & 0.00 & -0.14 & -0.03 & -0.13 & 0.05 & -0.10 & -0.05 & -0.08 & -0.04 \\
\hline Lawyer involvement & $-0.48 *$ & $-0.47^{*}$ & $-0.48^{*}$ & -0.26 & $-0.4 I^{*}$ & $-0.4 I^{*}$ & $-0.44 *$ & $-0.38 *$ & $-0.44 *$ & $-0.39 *$ \\
\hline Prior back/neck surgery & -0.17 & -0.13 & -0.05 & -0.01 & $-0.34^{*}$ & 0.16 & 0.04 & 0.01 & -0.18 & 0.06 \\
\hline Prior WCF claims & -0.09 & -0.15 & -0.22 & 0.04 & -0.06 & -0.06 & 0.00 & -0.14 & -0.12 & -0.05 \\
\hline Diagnostic nerve blocks & 0.21 & 0.17 & 0.12 & 0.10 & 0.20 & 0.19 & 0.21 & $0.29 *$ & 0.11 & 0.26 \\
\hline
\end{tabular}

Notes: aHigher scores equate to better outcomes/functioning. ${ }^{*} p \leq 0.05$.

Abbreviations: SF-36, Short-Form Health Survey-36; PF, physical functioning; RP, role-physical; BP, bodily pain; GH, general health; VT, vitality; SF, social functioning; RE, role-emotional; $\mathrm{MH}$, mental health; PCS, physical component summary; MCS, mental component summary; WCF, Workers' Compensation Fund.

predicting the SF-36 physical component summary (PCS) score is contained in Table 8 . As may be seen, the overall model was statistically significant $(F=4.85, p \leq 0.001)$ and resulted in an $R^{2}$ of 0.327 . Age and lawyer involvement were both statistically significant predictors of PCS scores. The regression model predicting the mental component summary score is presented in Table 9. As may be seen, the overall model was statistically significant $(F=3.92$, $p \leq 0.01$ ) with an $R^{2}$ of 0.282 with depression being the only statistically significant predictor in this model. In summary, age and lawyer involvement appeared to be the most robust predictors across the models. 
Table 7 Logistic regression equation predicting disability status with five pre-neurotomy variables as predictors

\begin{tabular}{lrrlll}
\hline Variable & $\boldsymbol{\beta}$ & Wald & p-value & Exp (B) & 95\% Cl \\
\hline Age & 0.07 & 4.44 & 0.04 & 1.08 & $1.01-1.15$ \\
Depression & 0.61 & 0.53 & 0.47 & 1.84 & $0.36-9.43$ \\
Lawyer involvement & 2.09 & 5.80 & 0.02 & 8.05 & $1.47-43.90$ \\
Prior back/neck surgery & 0.25 & 0.77 & 0.38 & 1.29 & $0.73-2.25$ \\
Prior WCF claims & 0.13 & 2.61 & 0.11 & 1.14 & $0.97-1.35$ \\
Constant & -7.77 & 11.45 & & 0.01 & \\
\hline
\end{tabular}

Note: Omnibus chi-square $=22.79, \mathrm{df}=5, p \leq 0.001$.

Abbreviations: $\mathrm{Cl}$, confidence interval; WCF, Workers' Compensation Fund.

Table 8 Simultaneous-entry multiple regression model predicting the SF-36 (v.2) physical component summary score

\begin{tabular}{|c|c|c|c|c|}
\hline \multirow[t]{3}{*}{ Variable } & \multicolumn{4}{|c|}{ Coefficients } \\
\hline & \multicolumn{2}{|c|}{ Unstandardized } & \multicolumn{2}{|c|}{ Standardized } \\
\hline & $\boldsymbol{\beta}$ & SE & $\boldsymbol{\beta}$ & $p$ \\
\hline Age & -0.258 & 0.107 & -0.315 & 0.019 \\
\hline Depression & -3.958 & 2.944 & -0.189 & 0.185 \\
\hline Lawyer involvement & -7.855 & 3.183 & -0.340 & 0.017 \\
\hline Prior back/neck surgery & 0.398 & 1.000 & 0.054 & 0.693 \\
\hline Prior WCF claims & -0.485 & 0.309 & -0.189 & 0.123 \\
\hline Constant & 57.899 & 7.610 & & \\
\hline
\end{tabular}

Note: Model summary: $p \leq 0.001, R=0.572, R^{2}=0.327$, adjusted $R^{2}=0.259$.

Abbreviations: SF-36, Short-Form Health Survey-36; SE, standard error; WCF, Workers' Compensation Fund.

Table 9 Simultaneous-entry multiple regression model predicting the SF-36 (v.2) mental component summary score

\begin{tabular}{llllll}
\hline Variable & \multicolumn{2}{l}{ Coefficients } & & \\
\cline { 2 - 3 } & \multicolumn{2}{l}{ Unstandardized } & & \multicolumn{2}{l}{ Standardized } \\
\cline { 2 - 3 } \cline { 5 - 6 } & $\boldsymbol{\beta}$ & SE & & $\boldsymbol{\beta}$ & $\boldsymbol{p}$ \\
\hline Age & -0.020 & 0.122 & & -0.022 & 0.869 \\
Depression & -8.898 & 3.379 & & -0.383 & 0.011 \\
Lawyer involvement & -6.642 & 3.653 & & -0.258 & 0.075 \\
Prior back/neck surgery & 1.859 & 1.148 & & 0.226 & 0.112 \\
Prior WCF claims & -0.135 & 0.355 & & -0.047 & 0.705 \\
Constant & 59.882 & 6.805 & & & \\
\hline
\end{tabular}

Note: Model summary: $p \leq 0.01, R=0.531, R^{2}=0.282$, adjusted $R^{2}=0.210$. Abbreviations: SF-36, Short-Form Health Survey-36; SE, standard error; WCF, Workers' Compensation Fund.

\section{Discussion}

The current study examined RFN outcomes and preprocedure predictors of outcomes in Utah workers via a retrospective cohort design. The total disability rate for RFN patients was $39 \%$, and $30.4 \%$ of patients felt that their pain level after neurotomy was better than expected. Thirty-seven percent of patients felt that their quality of life had improved following RFN. In general, patient outcomes in this study appeared significantly worse than in many prior RFN studies, and this is likely in part due to problematic patient selection and technique issues. The current study also demonstrated that pre-procedure psychological factors (positive history of depression), social factors (lawyer involvement in compensation case), and biological factors (i.e., increased age) were all predictive of poor RFN outcomes. This supports the use of a biopsychosocial perspective in conceptualizing RFN patients. It also points to the potential utility of using pre-procedure variables in assisting with identification of patients likely to have a poor response to RFN treatment.

One variable that proved to be a consistent predictor of outcomes is lawyer involvement in a patient's compensation claim. Retaining an attorney was associated with over 7 times the odds of post-surgical disability and was also consistently associated with greater functional impairment, more physical disability, increased bodily pain, and less vitality. Considering that this association has been seen in other studies of compensated patients receiving lumbar fusion and discectomy, ${ }^{21,22,27,28,33}$ there is clear impetus to investigate what aspects of litigation may be influencing the outcomes of spine patients. It may be that the process of utilizing a lawyer creates incentives for maintaining a disabled role.

We are aware of only one other study that found preprocedure depression to be a predictor of RFN outcomes, ${ }^{29}$ although this has been a consistent finding in the spine surgery literature. ${ }^{21,22,24,26}$ Although the precise mechanism of how depression negatively influences outcomes is unknown, we believe that depression likely exacerbates patients' pain experiences and also negatively influences expectations for recovery following medical interventions, and these issues in turn lead to chronicity.

This study conforms to recommendations by some researchers to increase the use of standardized measures across a broad array of multidimensional spine patient outcomes. ${ }^{34}$ This practice facilitates comparisons across other procedures that have used similar methods. Indeed, it was somewhat surprising that compared to compensated fusion and discectomy patients from Utah, the current sample showed poorer back/neck-specific functional impairments, higher levels of pain, and worse perceptions of their physical health. ${ }^{21,22,25,27,28}$ Such differences might be potentially explained by pre-intervention characteristic differences across these studies. For example, the mean age and rates of depression were somewhat higher in this study, and these are consistent predictors of worse outcomes across studies of compensated Utah patients. The course of zygapophyseal joint-related pain may also be chronic and progressive, and RFN is a time-limited solution that needs to be repeated for ongoing efficacy. 
This study provides a reasonably "real-world" description of both RFN patient selection procedures and outcomes within a compensation sample from the State of Utah. Interestingly, it is clear that the "gold standard" of patients receiving two "positive" pre-RFN diagnostic nerve blocks was only evident in $29.7 \%$ of this particular sample. The majority of patients $(70.3 \%)$ only received a single positive diagnostic block prior to RFN. Further, the criteria for defining "positive" blockade response varied significantly across practitioners: $15 \%$ viewed a $50 \%$ pain reduction as positive, $65 \%$ viewed $>80 \%$ pain reduction as positive, and $25 \%$ did not report their criteria for positive response in procedure reports. Given these data, there are likely several patients in this sample who did not meet the diagnostic criteria for zygapophyseal joint-related pain, and thus, some of the poor patient outcomes may be explained on this basis. However, we did code the blockade variable $(1=$ one nerve block; $2=$ two nerve blocks) and examined its correlation with both pre-intervention and outcome variables in this study. The blockade variable was not statistically significantly associated with any of the pre-intervention variables. Of the 16 possible correlations, only three were statistically significant: SCI physical restrictions $(r=-0.32, p<0.05)$, SCI pain medication use $(r=-0.29, p<0.05)$, and the SF-36 mental health subscale $(r=0.29, p<0.05)$. By way of interpretation, the presence of two positive nerve blocks was associated with less SCI physical restrictions, less pain medication usage, and greater SF-36 mental health functioning at post-procedure. These analyses suggest that the presence of one versus two pre-procedural positive nerve blocks was not differentially predictive of the majority of outcomes in our sample. Clearly, there is a disconnection between recommended RFN treatment guidelines and practice patterns in Utah, and this may be an issue across other states as well. Indeed, the predictive efficacy of utilizing dual diagnostic blocks (versus zero or one) in RFN is currently controversial as evidenced by the only RCT conducted on this matter. ${ }^{35}$ This study found that RFN patients who underwent no medial branch nerve blockade prior to RFN (compared to single or dual blocks) sustained the best outcomes.

Perhaps, the greatest limitation to this study is its retrospective design. Without a control group, it was not possible to make assertions about the clinical efficacy of the RFN procedure on injured workers. Certainly, changes in patient outcomes due to natural history, regression to the mean, and/or placebo effects could not be ruled out given this study design. ${ }^{36}$ Moreover, this design did not allow for careful control of pre-procedure diagnostic blocks or procedural technique, both factors clearly associated with RFN outcomes. Another limitation was the response rate of participants. Of the 101 patients in the study, 56 completed the telephone survey resulting in an overall response rate of $55.4 \%$. It is important to note that 34 participants could not be reached due to outdated contact information, which was likely linked to the fact that a large number of compensation claims were closed (42) at the time of follow-up. Claims that are closed are no longer being tracked by the WCFU, and therefore, personal contact information is not kept up to date. This, in turn, leads to the possibility that the large number of open cases created a more negatively biased patient sample, as open cases are indicative of ongoing patient disability. Another clear limitation of this study is generalizability of findings to other states and the US population. It may be that Utah's compensation system is unique in terms of approving such procedures, and this may have differentially influenced outcomes and predictors. It would be prudent to replicate this study across other states in order to determine if practice patterns, outcomes, and predictors of RFN remain consistent.

\section{Conclusion}

This is one of the first studies to examine outcomes and predictive correlates of RFN in a workers' compensation sample. The results suggest that a substantial number of patients experienced poor outcomes following RFN, and at least some of this variability can be explained on the basis of pre-procedure biopsychosocial variables.

\section{Disclosure}

The authors report no conflicts of interest in this work.

\section{References}

1. Deyo RA, Mirza SK, Martin BI. Back pain prevalence and visit rates: estimates from U.S. national surveys, 2002. Spine (Phila Pa 1976). 2006;31(23):2724-2727.

2. Dagenais S, Caro J, Halderman S. A systematic review of low back pain cost of illness studies in the United States and internationally. Spine J. 2008;8(1):8-20

3. Smith MD, McGahan WF. Treating back pain without breaking the bank. Bus Health. 1998;16(3):50-52.

4. Merskey H, Bogduk N. Classification of Chronic Pain: Descriptions of Chronic Pain Syndromes and Definitions of Pain Terms. Seattle, WA: IASP Press; 1994

5. Manchikanti L, Boswell MV, Singh V, Pampati V, Damron KS, Beyer CD. Prevalence of facet joint pain in chronic spinal pain of cervical, thoracic, and lumbar regions. BMC Musculoskelet Disord. 2004;5:15.

6. Manchukonda R, Manchikanti KN, Cash KA, Pampati V, Manchikanti L. Facet joint pain in chronic spinal pain: an evaluation of prevalence and false-positive rate of diagnostic blocks. J Spine Disord Tech. 2007;20(7):539-545.

7. Van Zundert J, Vanelderen P, Kessels A, van Kleef M. Radiofrequency treatment of facet-related pain: evidence and controversies. Curr Pain Headache Rep. 2012;16(1):19-25. 
8. Poetscher AW, Gentil AF, Lenza M, Ferretti M. Radiofrequency denervation for facet joint low back pain: a systematic review. Spine (Phila Pa 1976). 2014;39(14):E842-E849.

9. Manchikanti L. The growth of interventional pain management in the new millennium: a critical analysis of utilization in the medicare population. Pain Physician. 2004;7(4):465-482.

10. Bogduk N. Evidence-informed management of chronic low back pain with facet injections and radiofrequency neurotomy. Spine J. 2008;8(1):56-64.

11. Boswell MV, Colson JD, Sehgal N, Dunbar EE, Epter R. A systematic review of therapeutic facet joint injections in chronic spinal pain. Pain Physician. 2007;10(1):229-253.

12. Ketroser DB. Experiences with neurotomies. Spine (Phila Pa 1976). 2002;27(3):329-330.

13. Manchikanti L, Abdi S, Atluri S, et al. An update of comprehensive evidence-based guidelines for interventional techniques in chronic spinal pain. Part II: guidance and recommendations. Pain Physician. 2013;16(2 Suppl):S49-S283.

14. Manchikanti L, Falco FJ, Singh V, et al. An update of comprehensive evidence-based guidelines for interventional techniques in chronic spinal pain. Part I: introduction and general consideration. Pain Physician. 2013;16(2 Suppl):S1-S48.

15. Leclaire R, Fortin L, Lambert R, Bergeron YM, Rossignol M. Radiofrequency facet joint denervation in low back pain: a placebocontrolled clinical trial to assess efficacy. Spine (Phila Pa 1976). 2001; 26(13):1411-1416.

16. van Wijk RM, Geurts JW, Wynne HJ, et al. Radiofrequency denervation of lumbar facet joints in the treatment of chronic low back pain: a randomized, double-blind, sham lesion controlled trial. Clin J Pain 2005;21(4):331-344.

17. Cohen SP, Huang JH, Brummett C. Facet joint pain - advances in patient selection and treatment. Nat Rev Rheumatol. 2013;9(2):101-116.

18. MacVicar J, Borowczyk JM, MacVicar AM, Loughnan BM, Bogduk N. Lumbar medial branch radiofrequency neurotomy in New Zealand. Pain Med. 2013;14(5):639-645.

19. Dreyfuss P, Halbrook B, Pauza K, Joshi A, McLarty J, Bogduk N. Efficacy and validity of radiofrequency neurotomy for chronic lumbar zygapophysial joint pain. Spine (Phila Pa 1976). 2000;25(10): 1270-1277.

20. Atlas SJ, Tosteson TD, Hanscom B, et al. What is different about workers' compensation patients? Socioeconomic predictors of baseline disability status among patients with lumbar radiculopathy. Spine (Phila Pa 1976). 2007;32(18):2019-2026.

21. DeBerard MS, Masters KS, Colledge AL, Schleusener RL, Schlegel JD. Outcomes of posterolateral lumbar fusion in Utah patients receiving workers' compensation: a retrospective cohort study. Spine (Phila Pa 1976). 2001;26(7):738-746.
22. LaCaille RA, DeBerard MS, Masters KS, Colledge AL, Bacon W. Presurgical biopsychosocial factors predict multidimensional patient outcomes of interbody cage lumbar fusion. Spine J. 2005;5(1):71-78.

23. Silvers HR. Lumbar percutaneous facet rhizotomy. Spine (Phila Pa 1976). 1990;15(1):36-40.

24. Gatchel RJ, Gardea MA. Psychosocial issues: their importance in predicting disability, response to treatment, and search for compensation. Neurol Clin. 1999;17(1):149-166.

25. DeBerard MS, LaCaille RA, Spielmans G, Colledge A, Parlin MA. Outcomes and presurgery correlates of lumbar discectomy in Utah workers' compensation patients. Spine J. 2009;9(3):193-203.

26. Deyo RA, Nachemson A, Mirza SK. Spinal-fusion surgery - the case for restraint. N Engl J Med. 2004;350(7):722-726.

27. DeBerard MS, Masters KS, Colledge AL, Holmes EB. Presurgical biopsychosocial variables predict medical and compensation costs of lumbar fusion in Utah workers' compensation patients. Spine J. 2003;3(6):420-429.

28. DeBerard MS, Wheeler AJ, Gundy JM, Stein DM, Colledge AL. Presurgical biopsychosocial variables predict medical, compensation, and aggregate costs of lumbar discectomy in Utah workers' compensation patients. Spine J. 2011;11(5):395-401.

29. Streitberger K, Müller T, Eichenberger U, Trelle S, Curatolo M. Factors determining the success of radiofrequency denervation in lumbar facet joint pain: a prospective study. Eur Spine J. 2011;20(12): 2160-2165.

30. Stauffer RN, Coventry MB. Anterior interbody lumbar spine fusion. Analysis of Mayo Clinic series. J Bone Joint Surg Am. 1972;54(4):756-768.

31. Roland M, Morris R. A study of the natural history of back pain. Part I: development of a reliable and sensitive measure of disability in lowback pain. Spine (Phila Pa 1976). 1983;8(2):141-144.

32. Ware JE, Snow KK, Kosinski MA, Gandek MS. SF-36 Health Survey: Manual and Interpretation Guide. 2nd ed. Lincoln, RI: Quality Metric Incorporated; 2000.

33. Maghout Juratli S, Franklin GM, Mirza SK, WickizerTM, Fulton-Kehoe D. Lumbar fusion outcomes in Washington State workers' compensation. Spine (Phila Pa 1976). 2006;31(23):2715-2723.

34. Deyo RA, Battie M, Beurskens AJ, et al. Outcome measures for low back pain research. A proposal for standardized use. Spine (Phila Pa 1976). 1998;23(18):2003-2013.

35. Cohen SP, Williams KA, Kurihara C, et al. Multicenter, randomized, comparative cost-effectiveness study comparing 0,1 , and 2 diagnostic medial branch (facet joint nerve) block treatment paradigms before lumbar facet radiofrequency denervation. Anesthesiology. 2010;113(2):395-405.

36. Turner JA, Deyo RA, Loeser JD, Von Korff M, Fordyce WE. The importance of placebo effects in pain treatment and research. JAMA. 1994;271(20):1609-1614.

\section{Journal of Pain Research}

\section{Publish your work in this journal}

The Journal of Pain Research is an international, peer reviewed, open access, online journal that welcomes laboratory and clinical findings in the fields of pain research and the prevention and management of pain. Original research, reviews, symposium reports, hypothesis formation and commentaries are all considered for publication.

\section{Dovepress}

The manuscript management system is completely online and includes a very quick and fair peer-review system, which is all easy to use. Visit http://www.dovepress.com/testimonials.php to read real quotes from published authors. 